\title{
Use and abuse of psychiatric testimony
}

\author{
DEREK CHISWICK
}

Psychiatric consultations usually take place within the traditional framework of the doctor-patient relationship. The patient attends at the suggestion of his family doctor; he does so willingly, with symptoms or problems for which he seeks help. The psychiatrist examines and gives his advice on the basis of the clinical picture and the best interest of the patient. It is a familiar setting which forms the very basis of medical practice, and doctors come to regard that special relationship with the patient as sacrosanct. For his part, the patient is seeking help in respect of his symptoms and he is free to accept or reject the advice offered.

When a psychiatrist examines an individual at the request of the court most of the unspoken principles that govern the doctorpatient relationship are altered. The defendant, not the patient, is referred not by a medical man but by a layman, on behalf of the prosecution, defence, or sentencer. Whether he is a willing, an indifferent, or a reluctant attender, he attends not at his own initiative but at the suggestion of somebody else. His referral results from some aspect of his behaviour; in most cases he offers no subjective complaints of ill health. The referring agent may have an interest in the defendant's mental health but what he particularly seeks is medical evidence that will help him in processing the case through the criminal justice system. The doctor's customary concern for the medical welfare of the individual becomes secondary to the doctor's principal obligation, which is to the referring agent who requests and funds the psychiatric report. It is against this unusual background that psychiatric evidence is obtained and used by courts. This paper poses three questions and suggests that the legitimate use of psychiatric testimony may become unknowing misuse and more rarely wilful abuse.

\footnotetext{
University Department of Psychiatry, Royal Edinburgh Hospital, Edinburgh EH10 5HF

DEREK CHISWICK, MB, MRCPSYCH, senior lecturer in forensic psychiatry
}

\section{Are psychiatric witnesses really experts?}

Expert evidence is admissible only in respect of matters of medicine, science, or some specialist issue where the court cannot resolve the matter fairly without hearing specialist knowledge. The theoretical standpoint in respect of psychiatric evidence is clear: the court will accept psychiatric testimony when there is the possibility that the accused has some abnormality of mind. Explanations or discussions about the normal mind are not expert matters and in these cases the court has no need for psychiatrists. It is usual for experts to be asked about their credentials so that their status can be established and it is permissible, and sometimes customary, for experts to be questioned on the methods by which they reach their conclusions. Let us consider these in turn.

In practice the examination of psychiatric credentials is often cursory: verification that the witness is medically qualified and a member or fellow of the Royal College of Psychiatrists usually suffices. The lawyer's failure to inquire further may reflect his difficulty in knowing just what to ask to establish the skills of the witness. Inevitably the crucial test of the expert is his performance in the witness box, yet some of the most able clinicians may make dismal witnesses in court, and some witnesses, appearing impressive because they are dogmatic, may be clinically slipshod. Reviewing the American scene, Needell, ${ }^{1}$ identified three possibilities for potential abuse: "(i) experts who offer biased opinions, based on either calculated or unconscious prejudices; (ii) physicians lacking in psychiatric sophistication who offer expert psychiatric testimony; and (iii) fully qualified experts who, through inadvertence or laziness, perform examinations that do not serve as a professionally adequate basis for their conclusions."

A related issue is the attraction of the court itself; for some it is a most seductive arena. It may inflate feelings of self importance, provide a welcome relief from the familiar routine of hospital or clinic work, and bring financial rewards. Legal work is not therefore bound to corrupt the psychiatrist but his clinical judgment may be disturbed by the heady atmosphere of the court room and by the need to oversimplify complex issues. Like other medical experts, he will soon realise that the only aspects of his evidence that are of interest to the court are those which can be used to resolve the legal 
issues before it. In the adversarial arena fragments of clinical material are given exaggerated importance, extreme positions are adopted, and "judgments are paraded as objectively determined facts." This incitement of the psychiatrist to tailor his evidence provides opportunities for the unwary and the unscrupulous to produce psychiatric testimony on demand, in a stereotyped and unthinking manner, because experience dictates that such evidence relieves the court of its difficulties and is therefore welcomed.

The investigative techniques of expert witnesses are proper topics for inquiry in court. Psychiatrists reach their conclusions by considering all aspects of the case and by checking information from one source against that of another but they rely heavily on their face to face examination of the defendant. Psychiatrists acknowledge that their time honoured diagnostic method of history taking, mental state examination, and appraisal of other information is a subjective procedure in which the measuring instrument is the clinician himself. Unfortunately the calibration and standardisation of that instrument cannot easily be determined by cross examination in the court room. To the layman it is something of a mystery how the psychiatrist reaches his conclusions and lawyers in general find it difficult to inquire effectively into the basis for psychiatric evaluations. On both these issues, credentials and methods of evaluation, there is room for doubting the status of psychiatric testimony in comparison with that of other forensic evidence.

\section{What are the limits of psychiatric testimony?}

There is a long tradition whereby the law turns to medical men to give evidence relating to responsibility. The concepts and the phrases which have developed are legal terms - for example, "the mind," "mental responsibility," and "insanity"- which medicine has discarded. For example, psychiatrists examine the patient's mental state, not his mind, and in the general run of clinical practice they do not stop to consider the patient's responsibility for his symptoms or actions. The law continues to assume that these traditional concepts are proper subjects for psychiatric deliberation. The assumption has a certain face validity but little more and it might be argued that moral philosophers, behavioural scientists, or ministers of religion have an equally valid view on the mind and questions of individual responsibility; at present, however, psychiatrists and not philosophers give evidence in court.

Parallel with this medicalisation of responsibility is a trend, which started centuries ago when fixed penalties for crimes were abandoned, whereby society is constantly seeking mitigation for cases regarded as deserving. The special crime of infanticide and the defence of diminished responsibility provide two examples. The charge of infanticide, reduced from one of murder, depends wholly on evidence that relates the mother's homicidal act to an unbalanced mind resulting from the effects of childbirth. ${ }^{3}$ Among the generality of homicides mothers who kill their infants have always been regarded with some tolerance ${ }^{4}$ but the legal mechanism for showing compassion can be operated only with a psychiatric key. Although most infant killings result from a combination of personality, situational, and social factors the psychiatrist in court must distort and oversimplify these complex threads and pronounce that the unbalanced mind resulted from the effect of childbirth or, even more incredibly, from the effect of lactation (section 1, Infanticide Act 1938). Other contributory aspects to the killing may safely be ignored.

Similarly the defence of diminished responsibility does not have its basis in any psychiatric theory. It was not introduced in response to psychiatric innovations but in response to social and political pressures to see some convicted murderers escape the death penalty. But it is to psychiatry that society and the courts turn to help operate this quasimedical defence just as they had previously done and continue to do in respect of infanticide. Today not only does psychiatry push open the door to leniency but it is constantly being urged to open the door wider. Through the courts society has seen fit to expand the concept of diminished responsibility so that psychopathic disorder, depressive neurosis, dissociative states, and most recently the premenstrual syndrome 5 all have places within section 2 of the Homicide Act, 1957. Psychiatry has responded to social attitudes and to a contemporary desire to see some killers dealt with more leniently than others. This misapplication of psychiatric testimony is both demeaning and dangerous. The psychiatrist is required to stand in the witness box and utter the appropriate phrases-for example, "abnormality of mind" and "substantially impaired"-in accordance with the wording of section 2 . The evidence is rarely challenged and most cases are virtually accepted "on the nod."

But, though psychiatry may sometimes be a liberator, it may also function as the court's turnkey and enable it to deal with a defendant far more restrictively than would otherwise be possible. For offenders perceived as dangerous, committal to hospital with restrictions on discharge (section 41, Mental Health Act 1983) may result in a longer period of detention than would follow from a prison sentence. Thus the psychiatric witness may interest the court less for what he has to say than for what he can do.

In its discussion of the insanity defence, and in its proposal to abolish diminished responsibility the Butler report seemed to be looking for some retrenchment in the limits of psychiatric testimony. ${ }^{7}$ Such a move would be welcome and psychiatrists could then give evidence in relation to the single subject which rests exclusively within their province-namely, the diagnosis of mental illness. Most psychiatric evidence is supplied at the postconviction stage of proceedings in relation to disposal, but the restriction of psychiatric testimony to this issue would be a welcome step in the demedicalisation of criminal responsibility.

Unfortunately even here working practices give rise to potential sources of abuse. In short, so many non-patient variables are operating at the sentencing stage of the judicial procedure that chance, rather than clinical need, may decide the outcome. The court's decision to seek a report is essentially idiosyncratic so that entry of the convicted offender into the medical clearing house is determined arbitrarily. Once there, the chance of a medical recommendation for treatment may depend as much on the doctor as on the prisoner. The doctor's attitude towards mentally abnormal offenders, the resources available to him, the climate within his hospital, and the prisoner's home address, if he has one, are all potent determinants of outcome, perhaps more so than the clinical status of the convicted man.

The central difficulty is that the legal process is a clumsy and inappropriate device for delivering an individual into medical treatment. The court has certain tasks, and acting as a glorified outpatient clinic is not one of them. The cases have been delivered to the doctor by a legal agency, where non-clinical considerations, such as the need to determine guilt, to punish the offender, and to protect society, may be more important than is ensuring treatment for those in need.

If psychiatric skills are limited to matters of mental illness then it must be acknowledged that stepping beyond these limits increases the chances of misuse and abuse. There has been recent interest in testing the suggestibility of subjects under interrogation, ${ }^{8}$ although the full implications of the Miranda decision (concerning the mental fitness of an arrested person to make a confession when in police custody) in the United States have yet to reach Britain. ${ }^{9}$ It is a legitimate topic for psychiatric inquiry if the suggestibility of the accused results from mental illness or from mental handicap, where the judges' rules already provide guidance, ${ }^{10}$ but most cases will not be clear cut and will concern borderline issues such as emotional stress or fatigue. The opportunity here for clothing matters of common sense (which are best left for juries to decide) in pseudopsychiatric jargon will be great and the chief loser will be the status of psychiatric testimony.

\section{Have psychiatric ethics been overlooked?}

The use of psychiatric skills to aid the administration of the criminal justice system is bound to give rise to ethical problems for clinicians. In the course of the judicial and penal processes a series of important decisions must be made and thereby some thorny issues 
must be tackled. For example, which defendants are to be deemed not responsible for their crimes? From which offenders does society require special protection? Which prisoners warrant early release by the granting of parole? When can a mentally disordered offender be safely released from hospital care?

The relevance of psychiatry in helping to make any or all of these decisions is arguable. Indeed, whether and how a psychiatrist chooses to answer these questions depends on what Bazelon, a senior American judge, has described as the need for the psychiatrist to serve many masters. ${ }^{11}$ His manner of construing mental illness may be essentially narrow or broad. His personal views on deviant behaviour may be "soft left" or "hard right," and institutional pressures from employing hospital, court, prison, or society itself may be overwhelming.

For psychiatrists attempting to give advice the ethical problems are immense, although they have attracted little discussion in the United Kingdom and psychiatrists only occasionally concerned in forensic work may be unaware of the broader issues. Yet, as Rappeport has emphasised, it is precisely because forensic work is different from other clinical work that the particular ethical difficulties arise. ${ }^{12} \mathrm{He}$ cautions the psychiatrist undertaking court work to be aware that he enters "another house ... not the house of medicine but that of law-with its different motives, goals, and rules of conduct." Most importantly the doctor comes to the defendant not as a therapist, nor even as a practitioner of medicine, but as the agent of the lawyer, court, administration, or institution. Yet, once engaged in an interaction with the subject, the psychiatrist uses his medical skills to develop a relationship and to establish rapport so that he can obtain the necessary data to reach his conclusion. That conclusion will then be delivered to the employing agent for his benefit. Thus the forensic consultation represents the very antithesis of the customary doctor-patient relationship.

What steps can the psychiatrist with an ethical conscience take to preserve his integrity? He can warn the defendant of his right to remain silent and if he is not satisfied that the defendant has the capacity to understand the warning he can end the interview. He can point out that he is not acting as a medical man but as a hired agent and that what the defendant tells him might be to his disadvantage and most certainly will not remain confidential. In reaching his conclusions he will avoid idiosyncratic theory or novel suggestion and will carefully separate scientific knowledge from personal bias, particularly in relation to sensitive crimes such as sex offences. In the witness box he will declare the limits of his own skills and will make the point that other equally expert witnesses might take a different view from his own. He will be at pains to describe his own concepts of controversial psychiatric issues, such as psychopathic disorder and the prediction of dangerousness, emphasising the weaknesses as well as the strengths of his arguments. In respect of the legal question of responsibility he will urge the court not to overmedicalise the issue but suggest that it solicits expert advice on the social and moral determinants of the problem.

Clearly the psychiatric witness who takes on board all these strictures, which are derived largely from the observations of Rappeport, would have little of any practical value to say to the court. Indeed, only if the psychiatrist is prepared to disregard his ethical obligations, at least to some extent, can he be of any use as an expert witness.

\section{Conclusion}

Psychiatric testimony and those who give it are vulnerable, and the preservation of professional and ethical standards is at risk. It is fatuous to pretend that complex social issues, such as criminal responsibility and the prediction of dangerousness, can be addressed solely on the basis of psychiatric knowledge. The initiative for defining the limits and relevance of psychiatric skills rests with the profession; it is an initiative that should be seized.

\section{References}

1 Needell JE. Psychiatric expert witnesses: proposals for change. Am f Law Med 1980;6:425-49. 2 Bowden P. Madness or badness? Br f Hosp Med 1983;30:388-94.

3 O'Donovan M. The medicalisation of infanticide. Crim Law Rev 1984; May:259-64.

4 Smith R. Trial by medicine: insanity and responsibility in Victorian trials. Edinburgh: Edinburgh University Press, 1981 .
Unith R. Trial by medicine:

5 d'Orban PT. Medicolegal aspects of the premenstrual syndrome. Br $\mathcal{J}$ Hosp Med 1983;30:404-9. 6 Dell S. Murder into manslaughter: the diminished responsibility defence in practice. Maudsley Monograph No 27. Oxford: Oxford University Press, 1984.

7 Home Office and Department of Health and Social Security. Report of the committee on mentally abnormal offenders. Cmnd No 6244. London: HM Stationery Office, 1975.

8 Gudjonsson GH. Suggestibility, intelligence, memory recall and personality: an experimental study. Br f Psychiatry 1983;142:35-7.

9 Wulach JS. The assessment of competency to waive Miranda rights. 7 Psychiat Law 1981; Summer:209-20.

10 Home Office. Fudges rules and administrative directions to the police: Home Office Circular No 89/1978. London: HM Stationery Office, 1978.

11 Bazelon DL. The law, the psychiatrist, and the patient. Man Med 1980;5:77-86.

12 Rappeport JR. Ethics and forensic psychiatry. In Bloch S, Chodoff P, eds. Psychiatric ethics. Oxford: Oxford University Press, 1981:255-76.
Why do we revert to a primitive Laennec type of stethoscope for auscultation of the fetal heart?

An ideal stethoscope for general use would have a large, open chest piece, since the accumulator gathers sound in proportion to its area.' (A diaphragm is used only to filter out low pitched sounds and allow easier appreciation of the remaining high pitched sounds.) There would be a short distance between the chest and ear pieces, since the efficiency of sound transmission varies inversely with the volume of air in the stethoscope. The internal surface would be smooth, and the internal diameter of the tubing would be narrow-but not too narrow. According to Littmann the stethoscope merely transmits sounds and does not amplify them, though others have suggested that in a deep, trumpet shaped bell true amplification can take place. ${ }^{2}$ Laennec's original stethoscope-a wooden cylinder about a foot long ${ }^{3}$ - fits these criteria, and on objective testing "few modern stethoscopes show any significant acoustical improvement since the time of Laennec."2 Nevertheless, hearing is more efficient when binaural, ${ }^{2}$ and the binaural stethoscope was introduced into Britain in the $1880 \mathrm{~s},{ }^{4}$ though acceptance was slow. Its long flexible tubing allowed auscultation of different parts of the chest without awkward changes of position for patient and doctor, but an acoustical price had to be paid for the advantages of portability and flexibility.

The fetal stethoscope in general use today is the Pinard stethoscope, an old instrument but by no means the first used for fetal auscultation. ${ }^{3}$ Adolphe Pinard (1844-1934), a distinguished French obstetrician, went to Paris as a student in 1862, 36 years after Laennec's death. His stethoscope is wider and shorter than Laennec's, and its deep trumpet shape may allow amplification. ${ }^{2}$ Its wide bell easilv makes an airtight fit on the pregnant abdomen, whereas there would be gaps if it were applied to a bony chest: this is why modern stethoscopes have a relatively small bell. Tubing is unnecessary since only a small area of the abdomen is to be examined, and a diaphragm is unnecessary since fetal heart sounds are of lower frequency than maternal heart sounds. ${ }^{5}$ Its one disadvantage is that it is monaural; a binaural fetal stethoscope that may be strapped to the obstetrician's head is available but this has not gained popularity in Britain, presumably because it gives the doctor a rather arthropodal appearance. The choice of stethoscope is largely irrational, ${ }^{6}$ and, despite the apparently ideal design of the Pinard stethoscope, I prefer to use a conventional binaural stethoscope for fetal auscultation.-JAMES OWEN DRIFE, senior lecturer in obstetrics and gynaecology, Leicester.

1 Littmann D. An approach to the ideal stethoscope. FAMA 1961;178:504-5.

2 Ertel PY, Lawrence M, Brown RK, Stern AM. Stethoscope acoustics. Circulation 1966;34:889 909.

1969;62:477-83.

4 Morris S. The advent and development of the binaural stethoscope. Practitioner 1967;199:674-80.

5 Dawson JB. Auscultation and the stethoscope. Practitioner 1964;193:315-22.

6 Hampton CS, Chaloner A. Which stethoscope? Br Med F 1967;iv:388-90. 